\title{
Attenuated total reflection infrared (ATR-IR) spectroscopy of antigorite, chrysotile, and lizardite
}

\author{
Ilona SaKaguchi", Yui Kouketsu*, Katsuyoshi Michibayashi ${ }^{*}$ and Simon R. Wallis ${ }^{* *}$ \\ ${ }^{*}$ Graduate School of Environmental Studies, Nagoya University, Nagoya 464-8601, Japan \\ ${ }^{* *}$ Department of Earth and Planetary Environmental Science, the University of Tokyo, Tokyo 113-0033, Japan
}

\begin{abstract}
Attenuated total reflection infrared (ATR-IR) spectroscopy allows measurements to be made directly from the surface of one-sided, diamond polished thin sections of geological samples. This method greatly reduces the sample preparation time when compared to other IR spectroscopy methods and opens the possibility of using infrared spectroscopy to study thin-section scale microstructures. ATR-IR spectroscopy of antigorite, chrysotile, and lizardite in samples from the Mt. Shiraga serpentinite body, central Shikoku, SW Japan, reveals clear spectral differences in the $650-1250 \mathrm{~cm}^{-1}$ region associated with the vibration of the $\mathrm{Si}-\mathrm{O}$ bonds in $\mathrm{SiO}_{4}$ tetrahedra and in the $3300-3750 \mathrm{~cm}^{-1}$ region associated with the vibration of the $\mathrm{O}-\mathrm{H}$ bond in $\mathrm{MgO}_{2}(\mathrm{OH})_{4}$ octahedra. A data-processing algorithm developed in this study allows the absorbance intensity and wavenumber of a particular absorbance peak to be used to create serpentine mineral phase maps based on the highest intensity $\mathrm{Si}-\mathrm{O}$ absorbance bands for antigorite, chrysotile, and lizardite. Our methodology can be used to map serpentinite microstructures in thin sections illustrating the potential of ATR-IR as a relatively un-explored analytical tool in petrological studies. A combination of ATR-IR and electron microprobe data shows that for antigorite the wavenumber of the $\mathrm{O}-\mathrm{H}$ absorbance band is correlated with the Fe content. Metamorphic reactions of serpentine minerals play a key role in the hydrodynamics of the earth's lithosphere, and the new information on serpentine mineral hydroxyl group behavior obtained by applying the technique outlined in this study are of great potential interest to researchers in a wide range of different fields.
\end{abstract}

Keywords: Attenuated total reflection infrared (ATR-IR) spectroscopy, ATR-IR mapping, Serpentine minerals, Antigorite, Chrysotile, Lizardite

\section{INTRODUCTION}

Serpentine minerals, antigorite, chrysotile, and lizardite are hydrous sheet silicates that contain approximately 13 wt $\%$ of water. They are the main constituents of serpentinite rocks, which are formed when ultramafic rocks are hydrated. Metamorphic reactions of serpentine minerals play an important role in many subduction zone processes. For instance, it is thought that the dehydration of serpentine minerals can trigger partial melting in the subduction zone (Ulmer and Trommsdorff, 1995; Hattori and Guillot, 2003; Rüpke et al., 2004). There is also evidence that fluids released from serpentine minerals could be the cause for seismicity occurring in subduction zones at in-

\footnotetext{
doi:10.2465/jmps. 190807

I. Sakaguchi, sakaguchi.ilona.talvikki@j.mbox.nagoya-u.ac.jp Corresponding author

Y. Kouketsu, kouketsu.yui@nagoya-u.jp
}

termediate depths ( 50-300 km) (Peacock, 2001; Dobson et al., 2002; Hacker et al., 2003; Jung et al., 2004).

Different serpentine minerals are stable in different metamorphic conditions, and their formation is controlled by $P-T$ conditions, kinetic factors, and the composition of the metasomatic fluid (Evans, 2004). Furthermore, the differing coefficients of friction of serpentine minerals, especially the low coefficient of friction for chrysotile, have a significant impact on the faulting behavior of serpentinite rocks (Scholz, 2019). Therefore, reliable identification of antigorite, chrysotile, and lizardite and microstructural analysis of natural serpentinite samples are an important part of developing a better understanding of the metamorphic processes and fault zone dynamics of serpentinite rocks. However, this kind of research is hampered by a limited range of easy to use techniques that can distinguish different types of serpentinite minerals in standard petrographic thin sections. 
Identifying antigorite, chrysotile, and lizardite in thin section using a polarizing microscope or an electron microprobe can be challenging due to the similarity of their optical properties and chemical composition. A simplified general chemical formula for serpentine minerals is $\mathrm{X}_{3} \mathrm{Y}_{2} \mathrm{O}_{5}(\mathrm{OH})_{4}$, where $\mathrm{X}$ is usually occupied by $\mathrm{Mg}$ and $\mathrm{Y}$ by Si. However, natural samples exhibit considerable compositional variation. For instance, $\mathrm{Mg}$ can be substituted by various cations such as $\mathrm{Fe}^{2+}, \mathrm{Fe}^{3+}, \mathrm{Al}, \mathrm{Cr}, \mathrm{Ni}$ or $\mathrm{Mn}$ and $\mathrm{Si}$ by cations such as $\mathrm{Al}$ and $\mathrm{Fe}^{3+}$ (Moody, 1976; O’Hanley and Dyar, 1993).

Different types of serpentine show somewhat different ranges of chemical composition, but there is a large overlap and the main distinguishing feature is the crystal structure. The basic structure of all serpentine minerals is comprised of sheets of $\mathrm{SiO}_{4}$ tetrahedra that are covalently linked to a layers of $\mathrm{MgO}_{2}(\mathrm{OH})_{4}$ octahedra (Evans et al., 2013). In each of the main types of serpentine mineral, sheets of these basic units are stacked and bound together in a specific way forming a distinct crystal structure. Antigorite has a wavy, layered structure in which the orientation of the tetrahedral $\mathrm{SiO}_{4}$ layers is periodically reversed, chrysotile forms layered tubular structures that give chrysotile its typically fibrous appearance, and lizardite has a simple, layered structure.

Vibrational spectroscopic methods - Raman and infrared spectroscopy - can be used to identify minerals through observing the characteristic molecular vibration of the different functional groups. Raman spectroscopy and infrared spectroscopy are complementary methods as vibrational modes that are infrared active cannot be Raman active and vice versa. Several Raman studies have documented the characteristic Raman spectra of antigorite, chrysotile, and lizardite (e.g., Rinaudo et al., 2003; Enami, 2006). However, Raman spectroscopy of serpentine minerals tends to suffer from fluorescence effects (Groppo et al., 2006), which can make mineral identification more difficult.

Several previous studies (e.g., Farmer, 1974; Post and Borer, 2000; Šontevska et al., 2007) also describe the infrared spectra of serpentine minerals. Nearly all of these previous studies use transmission IR spectroscopy. Transmission IR spectroscopy requires that samples are either ground into a fine powder and pressed into discs thus losing microstructural information, or made into double polished thin sections of a specific thickness. In the case of serpentine minerals, the sample needs to be thinner than about 20 micrometers for a successful measurement. Preparation of such samples is time consuming and technically challenging.

Attenuated total reflection infrared (ATR-IR) spectroscopy is an alternative IR method, which utilizes an internal reflection element (IRE), also known as an ATR crystal, that allows measurements to be made directly from the surface of a normal polished thin section, which significantly reduces the time needed for sample preparation. In this paper, we studied the suitability of the ATR-IR method to distinguish antigorite, chrysotile, and lizardite. In addition, we applied the ATR-IR method to map areas with multiple mineral phases in order to demonstrate the possibilities of this technique in analyzing thin section scale microstructures.

\section{METHODS}

\section{Attenuated total reflection infrared (ATR-IR) spec- troscopy}

The ATR-IR spectra was measured with a Fourier transform infrared (FTIR) spectrometer (Nicolet iS10 by Thermo Fisher Scientific) equipped with a mercury cadmium telluride (MCT) detector at the Petrology Laboratory at Nagoya University. The FTIR spectrometer was attached to an infrared microscope (Nicolet Continuum by Thermo Fisher Scientific) and the instrument was purged with dry air and cooled by liquid nitrogen. The measurements were made using a germanium ATR crystal with an angle of incidence of $28^{\circ}$ and refractive index of 4 . The individual spot measurements were made from thin sections polished by diamond paste (grainsize $1 \mu \mathrm{m}$ ). The thin sections used for mapping were further polished using colloidal silica. $100 \times 100 \mu \mathrm{m}$ aperture, which corresponds to a $25 \times 25 \mu \mathrm{m}$ spot size, was used for the ATR-IR measurements. The step size for ATR-IR mapping varied between $25-50 \mu \mathrm{m}$. 32 scans were recorded for each individual measurement. In order to limit the mapping time, only 16 scans were recorded for each measurement during the ATR-IR mapping. A spectral range of $650-4000 \mathrm{~cm}^{-1}$ was recorded with a $4 \mathrm{~cm}^{-1}$ resolution for all ATR-IR measurements.

\section{Electron microprobe (EMPA)}

The compositions of the serpentine minerals were analyzed quantitatively by wavelength-dispersive spectrometer (WDS) by an electron probe microanalyzer (JXA8900R; JEOL) at the Petrology Laboratory of Nagoya University. The accelerating voltage of individual quantitative measurements was set to $15 \mathrm{kV}$ with a $12 \mathrm{nA}$ beam current and a $5 \mu \mathrm{m}$ beam spot diameter. For mapping, the accelerating voltage and the beam current were set to $20 \mathrm{kV}$ and $100 \mathrm{nA}$, respectively. The step size used for mapping was $5 \mu \mathrm{m}$. The correction factors calculated by Kato (2005) were employed for matrix correction. 


\section{SAMPLE DESCRIPTION}

Samples analyzed for this study are from the Mt. Shiraga serpentinite body, which is located in the Sanbagawa metamorphic belt in central Shikoku, SW Japan. The originally dunitic rocks of mantle wedge origin have been completely serpentinized and are surrounded by mafic, pelitic, and siliceous schists (Kawahara et al., 2016).

The most common serpentine mineral found in the Mt. Shiraga serpentinite body is antigorite. Antigorite is typically platy (Fig. 1a) but can also have a fibrous appearance. Chrysotile and lizardite were formed after the main antigorite-dominated serpentinization, and they are present in a limited number of samples, mostly found between the contact zone of the serpentinite body and the surrounding metasedimentary rocks. The chrysotile found in the Mt. Shiraga serpentinite body is characteristically fibrous (Fig. 1b). Lizardite is fine-grained and occurs in anastomosing veins, which appear reddish (Fig. 1c) due to the existence of iron-oxides. Remarkably, several samples contain all three serpentine minerals (Fig. 1d). These samples are of particular interest as they contain various reaction textures between serpentine minerals, which can be studied in detail using infrared spectroscopy. Raman spectroscopy was used to make the preliminary mineral identifications of serpentine minerals using the characteristic peaks proposed by Enami (2006). The Raman spectra of antigorite, chrysotile, and lizardite presented in this paper (Fig. 2) were measured from the same samples as the representative ATR-IR spectra for each respective serpentine mineral. In addition to the three serpentine minerals, the samples also contained olivine (of metamorphic origin), magnetite, brucite, and $\mathrm{Cr}$-spinel as well as some other minor accessory minerals, such as talc.

\section{RESULTS}

\section{ATR-IR spectra of serpentine minerals}

In order to choose representative spectra of antigorite, chrysotile, and lizardite, we selected 30 ATR-IR measurements (10 measurements of each mineral) and determined the wavenumber value of each absorbance band using the spectral peak fitting software PeakFit 4.12. From these 30 measurements, we chose the most representative spectra of antigorite, chrysolite, and lizardite to present in this study (Fig. 3). The measurement locations of these ATRIR spectra of antigorite, chrysotile, and lizardite are shown in Figure 1. All three serpentine minerals have two dominant vibrationally active domains in their crystal structure, which absorb radiation in two distinct parts of the mid-infrared region that was measured for this study $\left(650-4000 \mathrm{~cm}^{-1}\right)$. Detailed wavenumber values of all absorbance bands that were detected are listed in Table 1 along with results from previous IR studies of serpentine minerals made using the transmission IR method.

The lower wavenumber region $\left(650-1250 \mathrm{~cm}^{-1}\right)$ is associated with the vibration of the $\mathrm{Si}-\mathrm{O}$ bonds in the $\mathrm{SiO}_{4}$ tetrahedra of serpentine minerals (Deer et al., 2009). In this region, the biggest difference between the three serpentine minerals is the position of the highest intensity absorbance band. The highest intensity absorbance bands of antigorite, chrysotile, and lizardite are at $~ 959, \sim 941$, and $\sim 930 \mathrm{~cm}^{-1}$, respectively. Antigorite also has several low-intensity peaks in the low wavenumber region (650$1250 \mathrm{~cm}^{-1}$ ) that are not present in the spectra of chrysotile and lizardite. These absorbance bands are related to various lower energy Si-O vibrational modes (Šontevska et al., 2007) caused by the complex undulating crystal structure of antigorite.

The high wavenumber region $\left(3300-3750 \mathrm{~cm}^{-1}\right)$ is associated with the vibration of the $\mathrm{O}-\mathrm{H}$ bond in the $\mathrm{MgO}_{2}(\mathrm{OH})_{4}$ octahedra. In this region, the largest difference between the serpentine minerals is in the absorbance intensity and the overall number of absorbance peaks. In addition to the main absorbance peak at $3671 \mathrm{~cm}^{-1}$, antigorite has 4 subsidiary low-intensity peaks in the 3300 $3750 \mathrm{~cm}^{-1}$ region. Mellini et al. (2002) suggest the main antigorite peak is related to the inner $\mathrm{O}-\mathrm{H}$ stretching, and that the lower wavenumber peaks are related to variations in the O-H bond strength, which can be caused by octahedral substitutions of $\mathrm{Mg}$ by other cations. The chrysotile spectrum in this region is characterized by two peaks at $\sim 3680$ and $\sim 3643 \mathrm{~cm}^{-1}$, which are related to the inner and outer stretching vibration of the $\mathrm{O}-\mathrm{H}$ bond (Viti and Mellini, 1997). The $3300-3750 \mathrm{~cm}^{-1}$ region of lizardite is characterized by a sharp main absorbance peak at 3683 $\mathrm{cm}^{-1}$, which is also related to in-phase vibrations of $\mathrm{O}-\mathrm{H}$ groups (Balan et al., 2002a).

\section{Chemical compositions of serpentine minerals}

The chemical compositions of the representative antigorite, chrysotile, and lizardite are shown in Table 2. Antigorite is enriched in silicon in comparison to chrysotile and lizardite. This is because the crystal structure of antigorite can accommodate slightly more silicon due to the periodic reversals of the $\mathrm{SiO}_{4}$ tetrahedra in antigorite (Evans et al., 2013). Other minor compositional differences that we observed are: the higher aluminum content of chrysotile and the higher iron content of lizardite, which might be partly caused by the iron-oxides in the lizardite veins. These compositional variations are within 

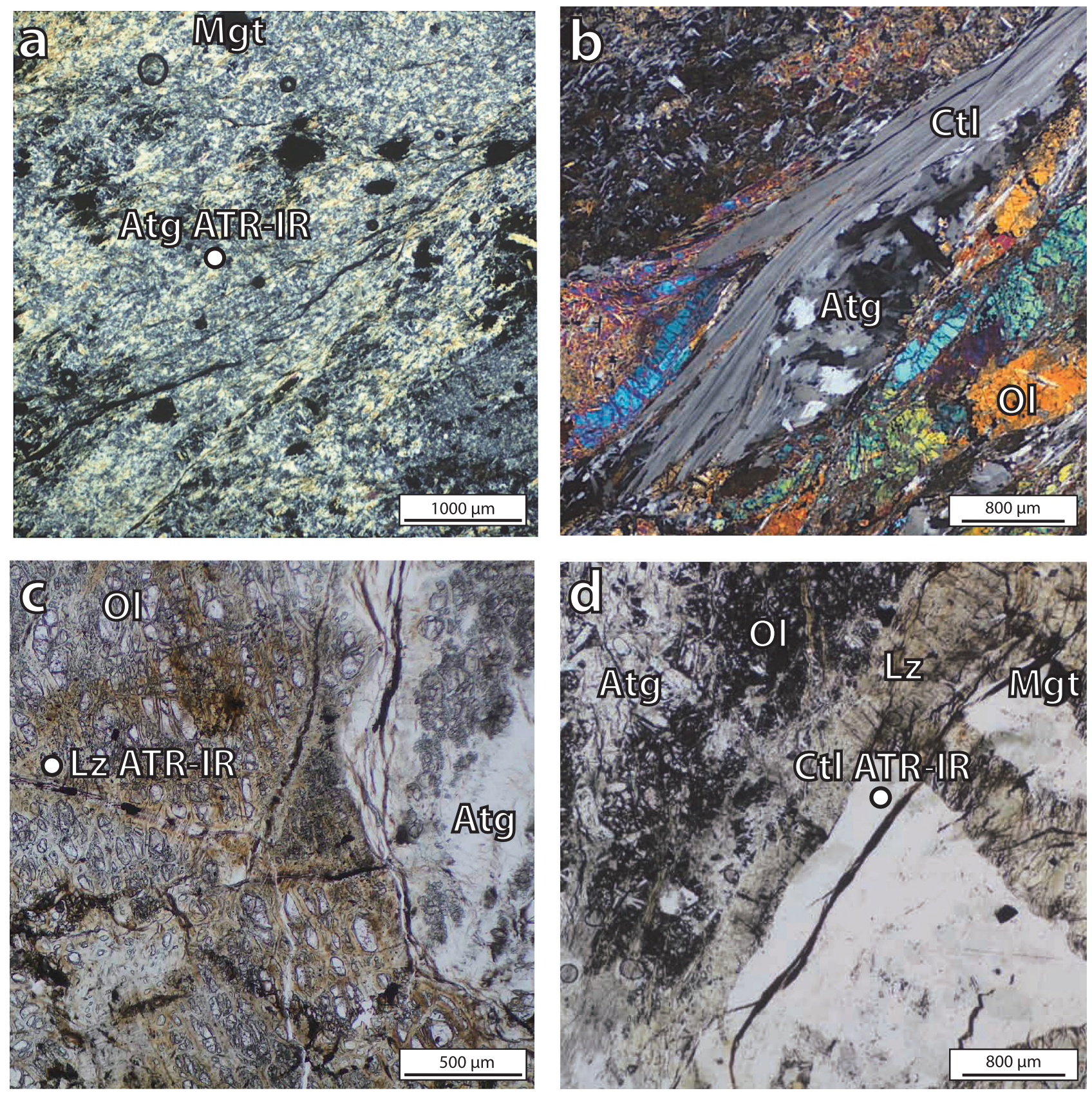

Figure 1. Thin section images of serpentine minerals from Mt. Shiraga serpentinite body taken in cross polarized light (XPL) and plane polarized light (PPL). (a) Antigorite from sample NSY7-15, XPL (b) Chrysotile vein that also contains antigorite in a matrix of antigorite and olivine. Sample NSY5-7, XPL. (c) Iron-oxide stained anastomosing lizardite veins running through a matrix of antigorite, olivine and magnetite. Sample KSY64, PPL. (d) A reaction zone of co-existing antigorite, lizardite and chrysotile with fine-grained olivine and magnetite. Sample KSY71, PPL. Atg, antigorite; Ctl, chrysotile; Lz, lizardite; Ol, olivine; Mgt, magnetite. The measurement locations of the ATR-IR spectra of antigorite, chrysotile and lizardite presented in this study are indicated.

the limits of regular serpentine mineral compositions published previously (e.g., Brindley and Wan, 1975; Peacock, 1987).

\section{ATR-IR mapping}

In order to examine the variation of serpentine mineral absorbance band wavenumber values in more detail, we developed an algorithm to process the ATR-IR mapping data. The algorithm uses the 'findpeaks' function, available in several software packages for numerical-analysis, to determine the wavenumber value and intensity of the highest intensity absorbance band in a set region of the ATR-IR spectra (Figs. 4a and 4b). 

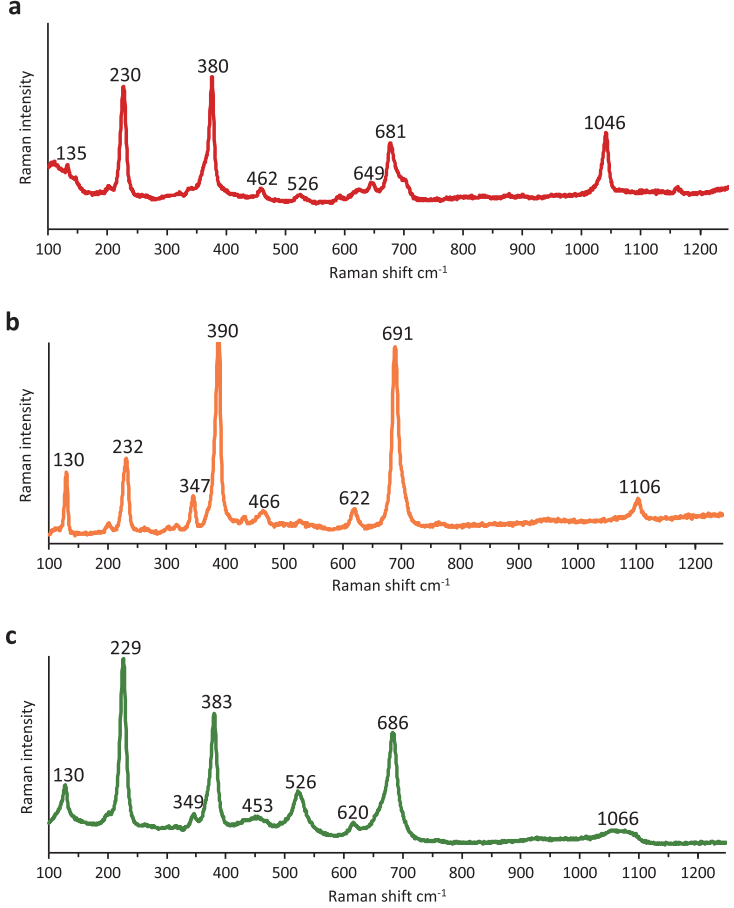
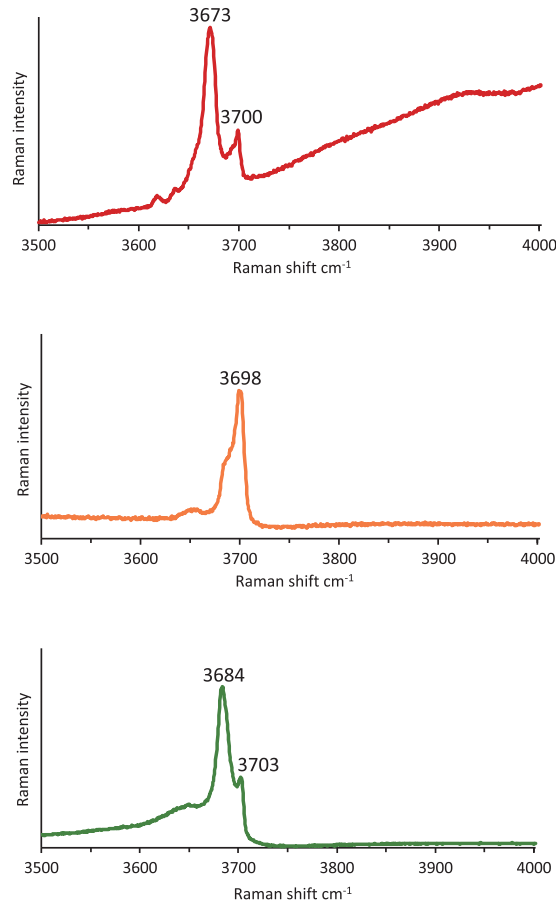

Figure 2. Raman spectra of (a) antigorite from sample NSY7-15, (b) chrysotile from sample KSY71 and (c), lizardite from sample KSY64.
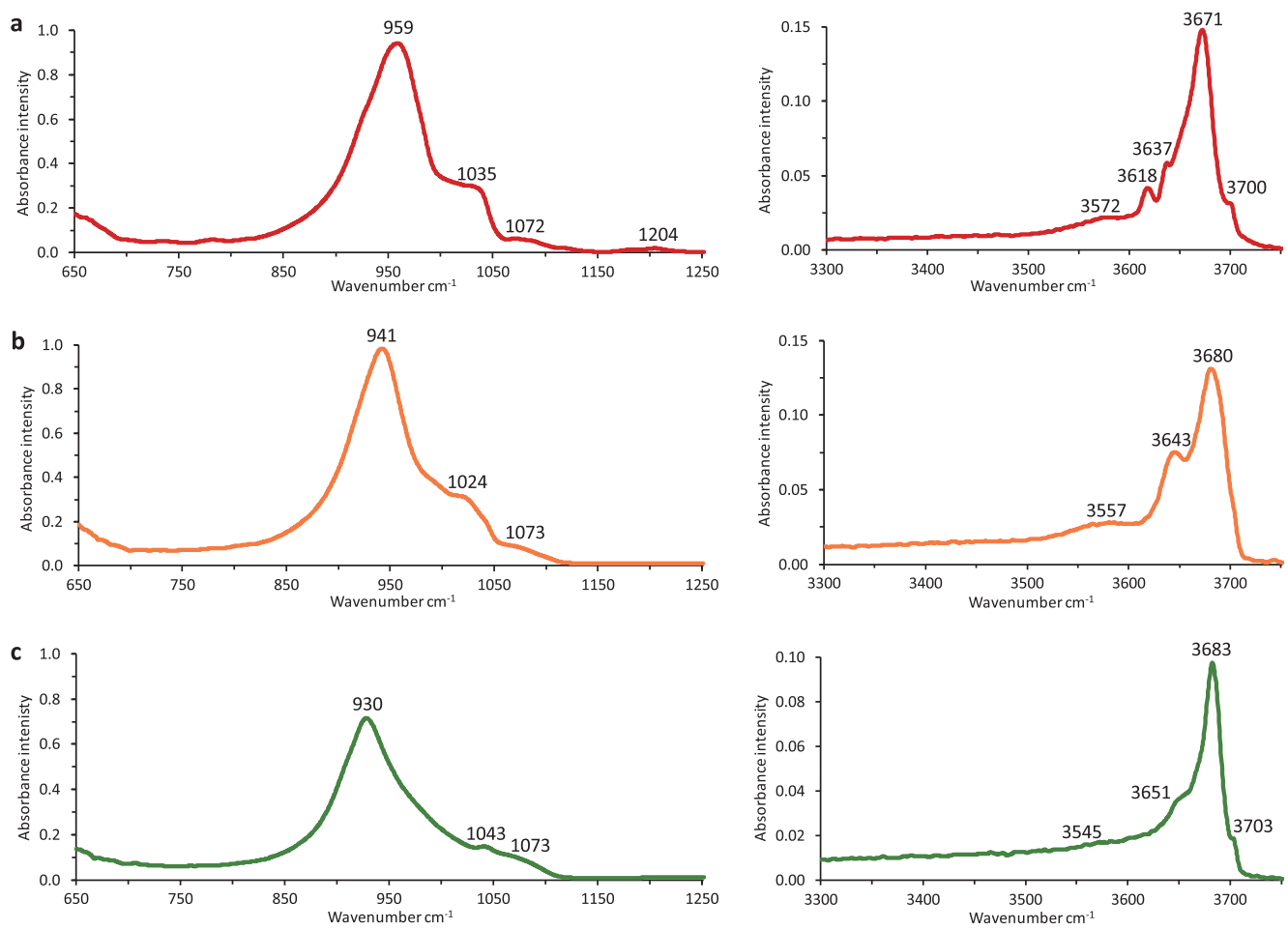

Figure 3. Representative ATR-IR spectra of (a) antigorite from sample NSY7-15, (b) chrysotile from sample KSY71, and (c) lizardite from sample KSY64.

Since each serpentine mineral has a characteristic highest intensity $\mathrm{Si}-\mathrm{O}$ absorbance band, it is possible to use this algorithm to create serpentine mineral phase maps
(Fig. 5). In addition to antigorite, chrysotile, and lizardite, the sample used in this study also contains a significant amount of olivine and some magnetite. The highest ATR- 


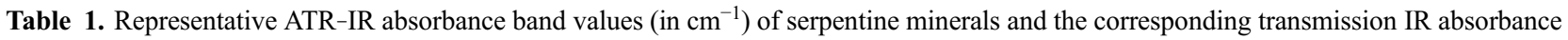
band values from previous studies

\begin{tabular}{|c|c|c|c|c|}
\hline \multicolumn{5}{|l|}{ Antigorite } \\
\hline This study & Post and Borer, 2000 & Šontevska et al., 2007 & Mellini et al., 2002 & Farmer, 1974 \\
\hline 959 & 990 & 987 & 983 & 994 \\
\hline 1035 & 1076 & 1083 & 1082 & 1077 \\
\hline 1072 & - & - & - & - \\
\hline 1204 & 1202 & 1205 & - & 1205 \\
\hline 3572 & 3568 & - & 3561 & - \\
\hline 3618 & 3620 & - & 3622 & - \\
\hline 3637 & 3652 & - & 3637 & - \\
\hline 3671 & 3673 & 3678 & 3678 & 3675 \\
\hline 3700 & 3697 & 3699 & 3700 & 3700 \\
\hline \multicolumn{5}{|l|}{ Chrysotile } \\
\hline This study & Post and Borer, 2000 & Šontevska et al., 2007 & Anbalagan et al., 2010 & Viti and Mellini, 1997 \\
\hline 941 & 958 & 961 & 965 & 956 \\
\hline 1024 & 1068 & 1078 & 1079 & 1072 \\
\hline 1073 & - & - & - & - \\
\hline 3557 & - & - & - & - \\
\hline 3643 & 3647 & 3646 & 3648 & 3640 \\
\hline 3680 & 3685 & 3688 & 3689 & 3688 \\
\hline \multicolumn{5}{|l|}{ Lizardite } \\
\hline This study & Post and Borer, 2000 & Balan et al., 2002a & Mellini et al., 2002 & Viti and Mellini, 1997 \\
\hline 930 & 959 & 948 & 951 & 952 \\
\hline 1043 & 1075 & 1080 & 1084 & 1088 \\
\hline 1073 & - & - & - & - \\
\hline 3545 & 3558 & 3584 & 3585 & 3586 \\
\hline 3651 & 3653 & 3645 & 3651 & - \\
\hline 3683 & 3685 & 3684 & 3684 & 3685 \\
\hline 3703 & - & 3703 & 3703 & - \\
\hline
\end{tabular}

Table 2. Chemical composition of the representative ATR-IR spectra of antigorite, chrysotile, and lizardite

\begin{tabular}{|c|c|c|c|}
\hline $\begin{array}{l}\text { Mineral } \\
\text { Sample }\end{array}$ & $\begin{array}{l}\text { Antigorite } \\
\text { NSY7-15 }\end{array}$ & $\begin{array}{l}\text { Chrysotile } \\
\text { KSY71 }\end{array}$ & $\begin{array}{l}\text { Lizardite } \\
\text { KSY64 }\end{array}$ \\
\hline $\mathrm{SiO}_{2} \mathrm{wt} \%$ & 44.27 & 41.60 & 39.29 \\
\hline $\mathrm{TiO}_{2}$ & 0.00 & 0.03 & 0.03 \\
\hline $\mathrm{Al}_{2} \mathrm{O}_{3}$ & 0.51 & 1.63 & 0.01 \\
\hline $\mathrm{Cr}_{2} \mathrm{O}_{3}$ & 0.33 & 0.38 & 0.00 \\
\hline $\mathrm{FeO}$ & 1.04 & 2.03 & 3.89 \\
\hline $\mathrm{MnO}$ & 0.03 & 0.02 & 0.08 \\
\hline $\mathrm{MgO}$ & 40.42 & 40.18 & 40.21 \\
\hline $\mathrm{NiO}$ & 0.14 & 0.08 & 0.25 \\
\hline Total & 86.75 & 85.95 & 83.75 \\
\hline \multicolumn{4}{|c|}{ Numbers of ions on the basis of $\mathrm{O}=7$} \\
\hline $\mathrm{Si}$ & 2.05 & 1.96 & 1.94 \\
\hline $\mathrm{Ti}$ & 0.00 & 0.00 & 0.00 \\
\hline $\mathrm{Al}$ & 0.03 & 0.09 & 0.00 \\
\hline $\mathrm{Cr}$ & 0.01 & 0.01 & 0.00 \\
\hline $\mathrm{Fe}$ & 0.04 & 0.08 & 0.16 \\
\hline $\mathrm{Mn}$ & 0.00 & 0.00 & 0.00 \\
\hline $\mathrm{Mg}$ & 2.79 & 2.83 & 2.95 \\
\hline $\mathrm{Ni}$ & 0.01 & 0.00 & 0.01 \\
\hline Sum cation & 4.93 & 4.98 & 5.06 \\
\hline $\mathrm{Mg \#}$ & 0.986 & 0.972 & 0.949 \\
\hline
\end{tabular}

Total iron is shown as $\mathrm{FeO}$.

$\mathrm{Mg} \#=[\mathrm{Mg} /(\mathrm{Mg}+\mathrm{Fe})]$
IR absorbance peak of olivine is at $\sim 866 \mathrm{~cm}^{-1}$, and it is included in the calculations (Fig. 4a). Magnetite does not have an distinct absorbance band in the $650-4000 \mathrm{~cm}^{-1}$ range (Chamritski and Burns, 2005), and thus the locations with magnetite are left blank in Figures 5 and 6.

In addition to mineral phase mapping, it is possible to use ATR-IR mapping to examine spectral variation of a single mineral. In order to illustrate this, we mapped a sample from Mt. Shiraga with antigorite veins running through an antigorite matrix (Fig. 6a). In this sample, the wavenumber values of the highest intensity $\mathrm{O}-\mathrm{H}$ absorbance peak vary between the veins and the matrix (Fig. 6b). The wavenumber values of $\mathrm{O}-\mathrm{H}$ absorbance bands of antigorite grains in the matrix are between 3660 and $3666 \mathrm{~cm}^{-1}$, while the antigorite grains in the veins tend to show higher values between 3666 and 3670 $\mathrm{cm}^{-1}$. To find out if the differences in the wavenumber values of $\mathrm{O}-\mathrm{H}$ absorbance bands might be caused by chemical composition, we mapped the chemical compositions of the sample using an electron microprobe. We measured the distribution of $\mathrm{Si}, \mathrm{Al}, \mathrm{Mg}, \mathrm{Fe}, \mathrm{Mn}, \mathrm{Cr}, \mathrm{Ni}$, and $\mathrm{Ti}$ in the sample and found that variations in the $\mathrm{Fe}$ concentration (Fig. 6c) were correlated with the $\mathrm{O}-\mathrm{H}$ absorbance values of antigorite (Fig. 6b). Quantitative mi- 

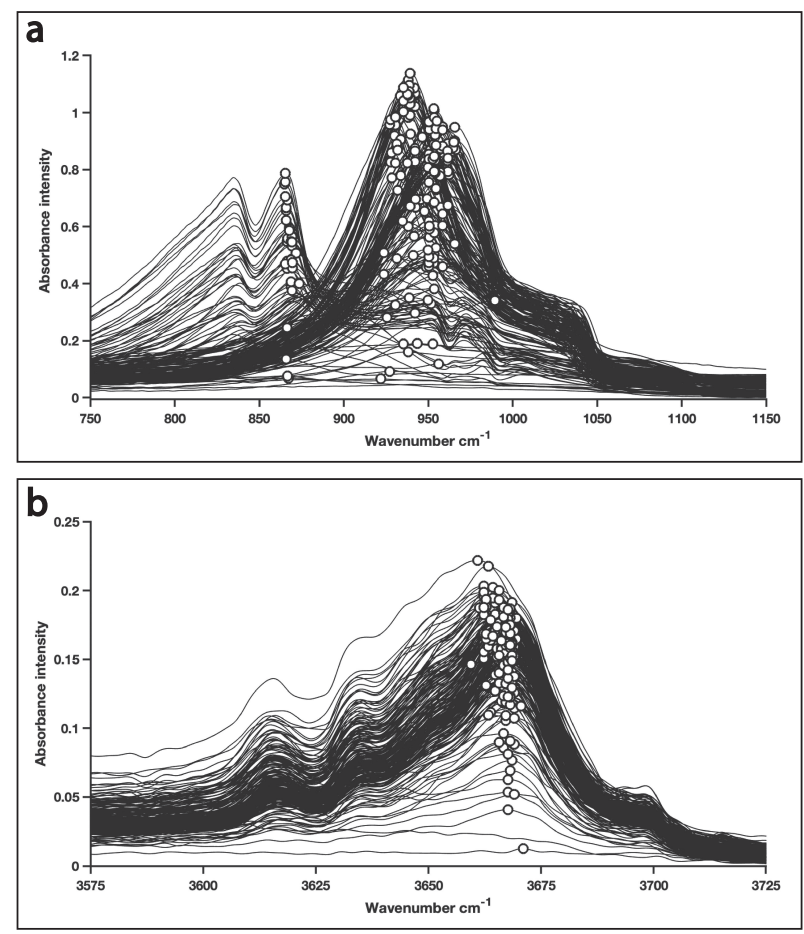

Figure 4. A representative selection of ATR-IR mapping spectra showing (a) the $750-1150 \mathrm{~cm}^{-1}$ region of sample KSY71 and (b) the $3575-3725 \mathrm{~cm}^{-1}$ region of sample KSY75. The white areas represent the highest intensity absorbance peaks of each individual measurement in this region as determined by the findpeaks function. The ATR-IR maps made from these datasets for samples KSY71 and KSY75 are displayed in Figures 5 and 6, respectively.

croprobe analyses show that Fe contents of antigorite range from 0.05 to $0.09 \mathrm{pfu}$ with lower concentrations in the veins than in the matrix (Fig. 6d).

\section{DISCUSSION}

The ATR-IR method has proven to be a reliable and simple method to measure the infrared spectrum of serpentine minerals. There are clear differences between the three serpentine minerals in the wavenumber values and overall shape of the spectra (Fig. 3). For instance, the highest intensity absorbance bands of antigorite, chrysotile, and lizardite have characteristic values of $\sim 959$, $\sim 941$, and $\sim 930 \mathrm{~cm}^{-1}$, respectively. The differences observed between the highest intensity absorbance bands of the three serpentine minerals are due to different $\mathrm{Si}-\mathrm{O}$ bond energies, which are the result of varying bond lengths related to the contrasting crystal structures of different serpentine minerals (Mellini et al., 2002).

The majority of the ATR-IR spectroscopy absorbance bands of serpentine minerals recognized in this study are in good agreement with previously published
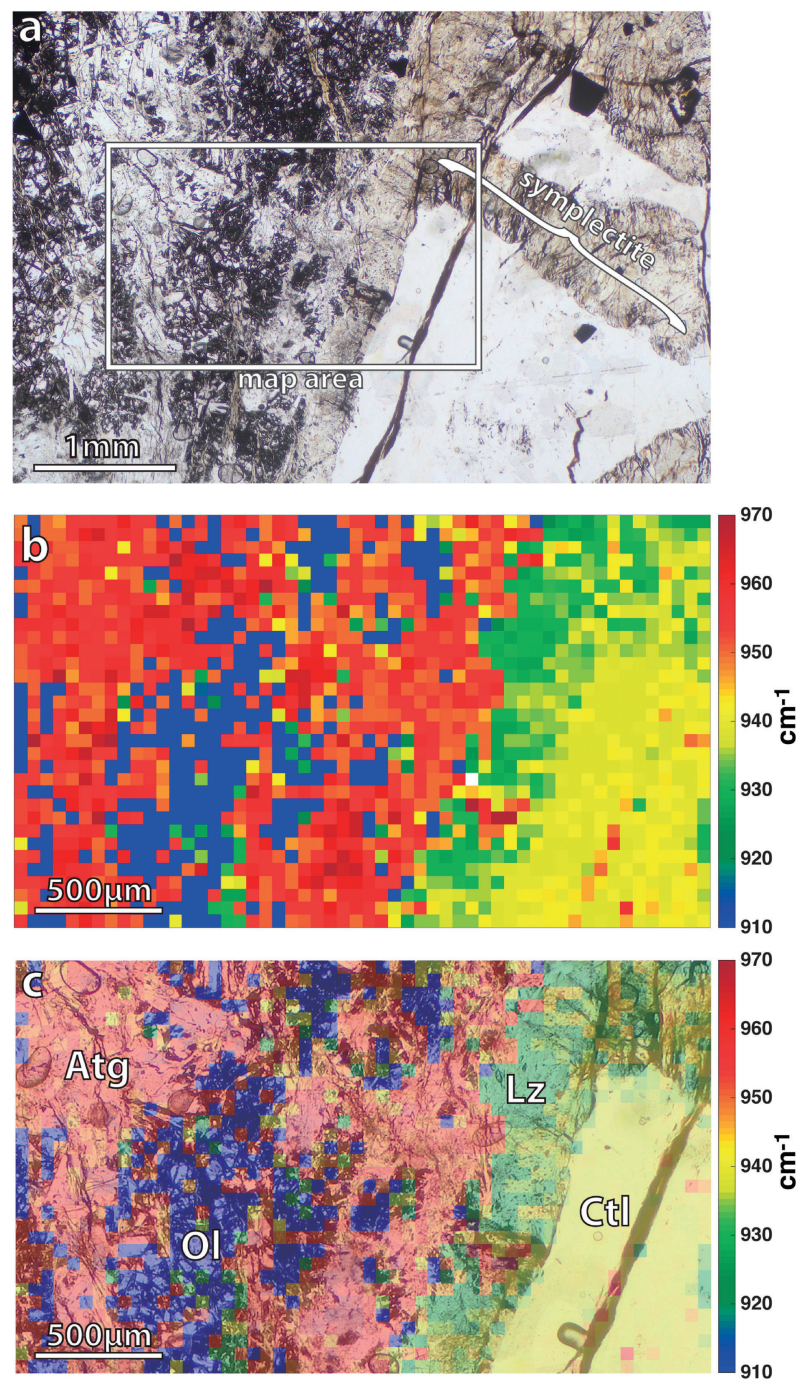

Figure 5. (a) A plane polarized thin section image of sample KSY71, containing all three serpentine minerals and showing reaction textures between the different serpentine minerals. (b) An ATR-IR map of the indicated area in (a) showing the wavenumber values of highest intensity absorbance peaks in the 650$1250 \mathrm{~cm}^{-1}$ region. Mapping step size was $50 \mu \mathrm{m}$. (c) A comparison between the ATR-IR map of sample KSY71 and a plane polarized thin section image of the mapped area. The sample contains antigorite (Atg in red areas), chrysotile (Ctl in yellow areas), lizardite ( $\mathrm{Lz}$ in green areas) and olivine (Ol in blue areas).

studies (Table 1). A larger number of low-intensity bands in the ATR-IR spectra were observed in this study than in some of the previous transmission IR studies. This could be due to the difficulty of distinguishing the lower absorbance peaks from background noise or simply due to the difference in how previous workers catalogued their observations. The high-intensity absorbance bands in the transmission IR spectra tend to have higher wavenumber values than the high-intensity ATR-IR absorbance bands. For example, in the transmission IR studies 

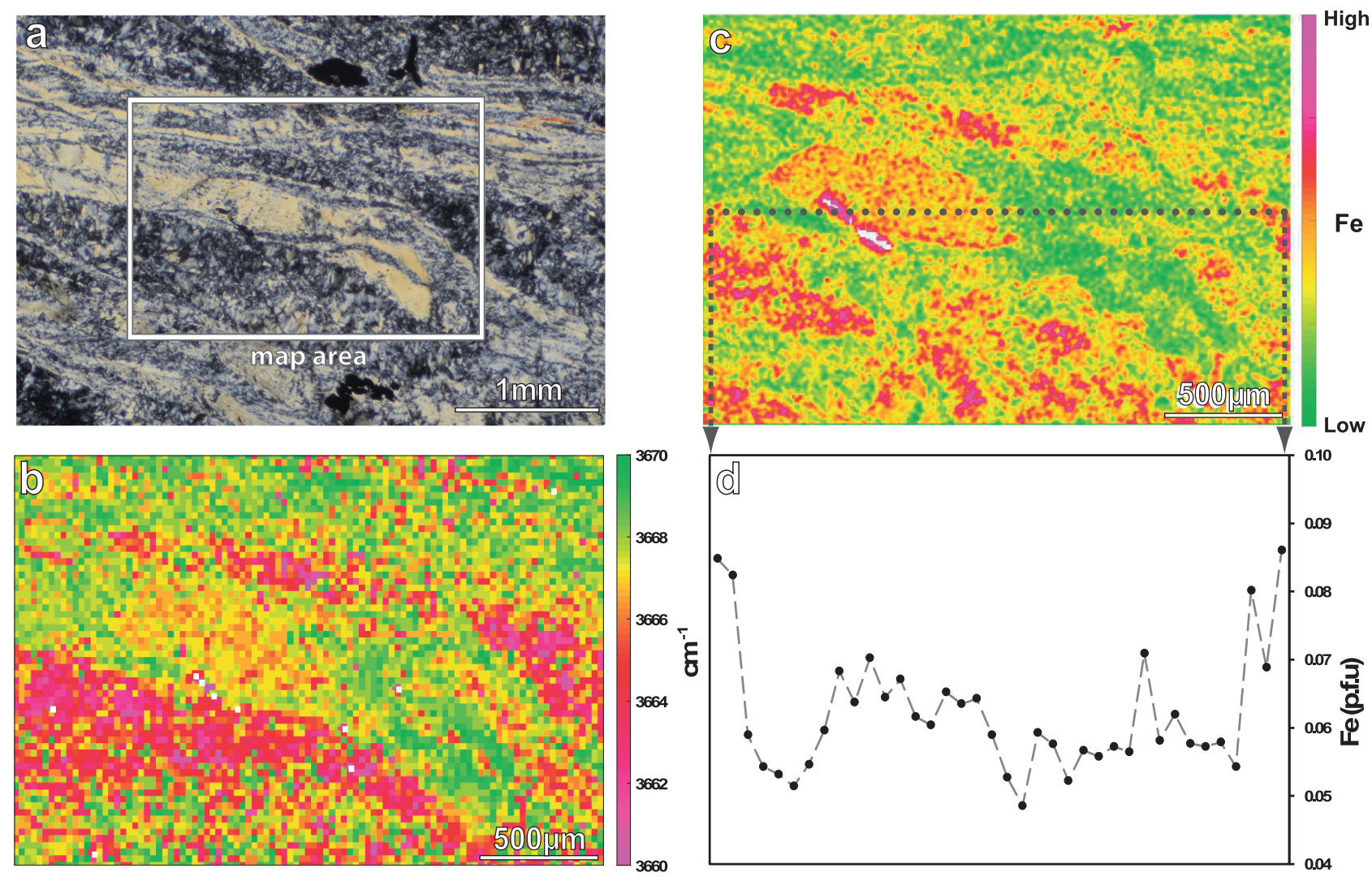

Figure 6. (a) A cross-polarized thin section image of antigorite veins running through an antigorite matrix in sample KSY75. (b) An ATR-IR map of the indicated area in (a) showing the wavenumber values of the highest intensity O-H absorbance bands of antigorite in the 3300$3750 \mathrm{~cm}^{-1}$ region. In addition to antigorite, this map also includes minor amounts of magnetite (white areas). Mapping step size was $25 \mu \mathrm{m}$. (c) An EPMA map of relative Fe concentration in antigorite measured from the indicated area in (a). The original mapping step size was 5 $\mu \mathrm{m}$, but each pixel in the map is recalculated to show average values from an area of $25 \times 25 \mu \mathrm{m}$ for the purpose of comparing the relative $\mathrm{Fe}$ concentration to the wavenumber values of antigorite $\mathrm{O}-\mathrm{H}$ absorbance bands. (d) Fe concentrations of antigorite per formula unit (pfu) on the basis of $\mathrm{O}=7$ from the cross-section indicated in (c).

the highest intensity absorbance band of antigorite has a wavenumber value nearly $30 \mathrm{~cm}^{-1}$ higher than the corresponding band observed in the ATR-IR spectra. The differences in the serpentine mineral absorbance band positions observed between the ATR-IR measurements and the previously published transmission IR studies are caused by the different ways in which light interacts with the sample in the different infrared spectroscopy methods. Spectral distortions are common in transmission IR measurements made using $\mathrm{KBr}$ pellet samples because electrostatic interactions between different particles in a powdered sample influence the whole macroscopic electric field of the sample (Balan et al., 2011). The ATR-IR method is also susceptible to spectral distortions, because the difference in refractive indices of the sample and the ATR crystal causes anomalous dispersion of infrared radiation at the interface resulting in shifts of the spectral peaks (Woods and Bain, 2014). This means that the ATRIR spectra of serpentine minerals will be slightly different when measurements are made with ATR crystals with different refractive indices.

This study clearly highlights some of the difficulties faced when trying to distinguish different serpentine minerals from each other using polarizing microscope techniques and how ATR-IR mapping can resolve some of these issues. For example, in the thin section image of sample KSY71 (Fig. 5a) both the lizardite and antigorite domains show similar discoloration by iron-oxides, and there is no clear contrast in the associated crystal habits meaning that the boundary between these two mineral domains is unclear. However, an overlay of the ATRIR map on the thin section image (Fig. 5c) clearly reveals the location of the boundary. The inverse situation can also be observed. The boundary between chrysotile and lizardite domains appears sharp in the thin section image of sample KSY71 (Fig. 5a). However, the ATR-IR map reveals the presence of a boundary zone between the two domains with a symplectitic intergrowth of lizardite and chrysotile (Fig. 5b). On closer inspection, symplectitic intergrowths can also be observed in some other sections 
of the boundary between chrysotile and lizardite (Fig. 5a). Such intergrowths in serpentine minerals have been previously reported (Bailey and Banfield, 1995; Dódony and Buseck, 2004), and the ATR-IR technique offers a simple way to recognize and image them. We also note that although coloration and other features may allow different types of serpentinite to be distinguished under the polarizing microscope, these features are not consistent between different samples and some other method, such as that proposed here, is required to identify the particular mineral species.

Other factors that can also have an effect on the observed infrared spectra are variations in crystallographic orientation and compositional changes. Balan et al. (2002b) studied the effect of crystallographic orientation on the ATR-IR spectra of chrysotile. According to their observations the wavenumber value of the highest intensity absorbance peak of chrysotile varied between 938$957 \mathrm{~cm}^{-1}$ depending on the crystallographic orientation. Such large variation was not observed in this study, perhaps suggesting that chrysotile in our sample has a strong crystallographic preferred orientation.

Studying variations in serpentine mineral $\mathrm{O}-\mathrm{H}$ absorbance bands is of particular interest to many researchers as it can further our knowledge of the hydration and dehydration reactions of serpentinites. Figure 6 illustrates how changes in chemical composition can affect the $\mathrm{O}-\mathrm{H}$ absorbance bands of serpentine minerals. A comparison between the ATR-IR map of wavenumber values of the $\mathrm{O}-\mathrm{H}$ absorbance band of antigorite and the EMPA map of Fe distribution shows a close correspondence (Figs. 6b and $6 \mathrm{c})$. Areas with high iron contents $(\sim 0.09 \mathrm{pfu})$ have up to $10 \mathrm{~cm}^{-1}$ lower $\mathrm{O}-\mathrm{H}$ absorbance values than areas with lower iron contents ( 0.05 pfu) (Figs. 6b and $6 \mathrm{~d}$ ). This observation is in line with the suggestion made by Mellini et al. (2002) that the octahedral substitution of $\mathrm{Mg}$ by $\mathrm{Fe}^{2+}$ would shift the main $\mathrm{O}-\mathrm{H}$ absorbance band of antigorite to lower wavenumbers. Other elemental substitutions for example Si by Al, have also been observed to have a large impact on the IR spectra of serpentine minerals (e.g., Serna et al., 1979; Velde, 1980). However, any other clear correlations between the ATR-IR and EMPA maps were not observed in this study.

While ATR-IR maps of individual absorbance bands are useful in illustrating spectral variations and studying their connection to serpentinite microstructures, it is better to examine the whole serpentine mineral spectrum when making a mineral identification. As mentioned above, the intensities and wavenumber values of individual absorbance bands can be affected by several factors, such as variations in mineral microstructure, crystallographic orientation, and chemical composition, and more work is necessary to study how such factors affect the ATR-IR spectra of serpentinite minerals.

\section{CONCLUSIONS}

Our study shows that the ATR-IR method is well suited to the in situ identification of serpentine minerals. The ease of making measurements directly from the surface of a thin section means the ATR-IR method has a considerable as yet largely un-explored potential in the field of mineral spectroscopy. This study also demonstrates that using a data-processing algorithm can be useful in teasing out small-scale fluctuations in absorbance intensities and wavenumber values of individual absorbance peaks in large ATR-IR mapping datasets. Such an approach shows that Fe concentration can have a noticeable effect on the wavenumber values of antigorite $\mathrm{O}-\mathrm{H}$ absorbance bands. More detailed ATR-IR mapping of serpentinite microstructures, such as veining, in combination with other petrological methods, such as EPMA mapping, can further improve our knowledge of the serpentinization processes.

\section{ACKNOWLEDGMENTS}

We thank the members of Nagoya University petrology group for helpful discussions and comments on this study. We express special thanks to H. Kawahara and T. Nagaya for supplying the samples collected from Mt. Shiraga and used in this study. We would also like to thank the two anonymous reviewers who reviewed this paper and the editor of JMPS, Dr. Masaki Enami, for their invaluable comments and advice. The work was partially supported by JSPS KAKENHI Grant Number JP16H06476 and JP16H06347 to S.W. and K.M., respectively. I.S. was supported by the Scholarship of Ministry of Education, Culture, Sports, Science and Technology Japan.

\section{REFERENCES}

Anbalagan, G., Sivakumar, G., Prabakaran, A.R. and Gunasekaran, S. (2010) Spectroscopic characterization of natural chrysotile. Vibrational Spectroscopy, 52(2), 122-127.

Bailey, S.W. and Banfield, J.F. (1995) Derivation and identification of nonstandard serpentine polytypes. American Mineralogist, 80, 1104-1115.

Balan, E., Saitta, A.M., Mauri, F., Lemaire, C. and Guyot, F. (2002a) First-principles calculation of the infrared spectrum of lizardite. American Mineralogist, 87, 1286-1290.

Balan, E., Mauri, F., Lemaire, C., Brouder, C., et al. (2002b) Multiple Ionic-Plasmon Resonances in Naturally Occurring Multiwall Nanotubes: Infrared Spectra of Chrysotile Asbestos. Physical Review Letters, 89.

Balan, E., Delattre, S., Roche, D., Segalen, L., et al. (2011) Line- 
broadening effects in the powder infrared spectrum of apatite. Physics and Chemistry of Minerals, 38, 111-122.

Brindley, G.W. and Wan, H.-M. (1975) Compositions, structures, and thermal behavior of nickel-containing minerals in the lizardite-nepouite series. American Mineralogist, 60, 863-871.

Chamritski, I. and Burns, G. (2005) Infrared- and Raman-Active Phonons of Magnetite, Maghemite, and Hematite: A Computer Simulation and Spectroscopic Study. Journal of Physical Chemistry B, 109, 4965-4968.

Deer, W.A., Howie, R.A. and Zussman, J. (2009) Rock Forming Minerals Volume 3B: Layered Silicates Excluding Micas and Clay Minerals, 2nd Revised edition. pp. 336, Geological Society of London.

Dobson, D.P., Meredith, P.G. and Boon, S.A. (2002) Simulation of Subduction Zone Seismicity by Dehydration of Serpentine. Science, 298, 1407-1410.

Dódony, I. and Buseck, P.R. (2004) Serpentines Close-Up and Intimate: An HRTEM View. International Geology Review, 46, 507-527.

Enami, M. (2006) Mineralogical methods for identification of asbestos and their limitations. Japanese Magazine of Mineralogical and Petrological Sciences, 35, 11-21.

Evans, B.W. (2004) The Serpentinite Multisystem Revisited: Chrysotile Is Metastable. International Geology Review, 46, 479-506.

Evans, B.W., Hattori, K. and Baronnet, A. (2013) Serpentinite: What, Why, Where? Elements, 9, 99-106.

Farmer, V.C. (1974) The Infrared spectra of minerals, Monograph, 4. pp. 539, Mineralogical Society of Great Britain and Ireland.

Groppo, C., Rinaudo, C., Cairo, S., Gastaldi, D. and Compagnoni, R. (2006) Micro-Raman spectroscopy for a quick and reliable identification of serpentine minerals from ultramafics. European Journal of Mineralogy, 18, 319-329.

Hacker, B.R., Peacock, S.M., Abers, G.A. and Holloway, S.D. (2003) Subduction factory 2. Are intermediate-depth earthquakes in subducting slabs linked to metamorphic dehydration reactions? Journal of Geophysical Research: Solid Earth, 108.

Hattori, K.H. and Guillot, S. (2003) Volcanic fronts form as a consequence of serpentinite dehydration in the forearc mantle wedge. Geology, 31, 525-528.

Jung, H., Green II, H.W. and Dobrzhinetskaya, L.F. (2004) Intermediate-depth earthquake faulting by dehydration embrittlement with negative volume change. Nature, 428, 545-549.

Kato, T. (2005) New Accurate Bence-Albee $\alpha$-Factors for Oxides and Silicates Calculated from the PAP Correction Procedure. Geostandards and Geoanalytical Research, 29, 83-94.

Kawahara, H., Endo, S., Wallis, S.R., Nagaya, T., et al. (2016) Brucite as an important phase of the shallow mantle wedge: Evidence from the Shiraga unit of the Sanbagawa subduction zone, SW Japan. Lithos, 254-255, 53-66.

Mellini, M., Fuchs, Y., Viti, C., Lemaire, C. and Linarès, J. (2002) Insights into the antigorite structure from Mössbauer and FTIR spectroscopies. European Journal of Mineralogy, 14, 97-104.

Moody, J.B. (1976) Serpentinization: a review. Lithos, 9, 125-138.

O'Hanley, D.S. and Dyar, M.D. (1993) The compositionof lizardite $1 \mathrm{~T}$ and the formation of magnetitein serpentinites. American Mineralogist, 78, 391-404.

Peacock, S.M. (1987) Serpentinization and infiltration metasomatism in the Trinity peridotite, Klamath province, northern California: implications for subduction zones. Contributions to Mineralogy and Petrology, 95, 55-70.

Peacock, S.M. (2001) Are the lower planes of double seismic zones caused by serpentine dehydration in subducting oceanic mantle? Geology, 29, 299-302.

Post, J.L. and Borer, L. (2000) High-resolution infrared spectra, physical properties, and micromorphology of serpentines. Applied Clay Science, 16, 73-85.

Rinaudo, C., Gastaldi, D. and Belluso, E. (2003) Characterization of chrysotile, antigorite and lizardite by FT-Raman spectroscopy. Canadian Mineralogist, 41, 883-890.

Rüpke, L.H., Morgan, J.P., Hort, M. and Connolly, J.A.D. (2004) Serpentine and the subduction zone water cycle. Earth and Planetary Science Letters, 223, 17-34.

Scholz, C.H. (2019) The Mechanics of Earthquakes and Faulting. pp. 517, Cambridge University Press.

Serna, C.J., White, J.L. and Velde, B.N. (1979) The effect of aluminium on the infra-red spectra of $7 \AA$ trioctahedral minerals 1. Mineralogical Magazine, 43, 141-148.

Šontevska, V., Jovanovski, G. and Makreski, P. (2007) Minerals from Macedonia. Part XIX. Vibrational spectroscopy as identificational tool for some sheet silicate minerals. Journal of Molecular Structure, 834-836, 318-327.

Ulmer, P. and Trommsdorff, V. (1995) Serpentine Stability to Mantle Depths and Subduction-Related Magmatism. Science, 268, $858-861$.

Velde, B. (1980) Ordering in synthetic aluminous serpentines; infrared spectra and cell dimensions. Physics and Chemistry of Minerals, 6, 209-220.

Viti, C. and Mellini, M. (1997) Contrasting chemical compositions in associated lizardite and chrysotile in veins from Elba, Italy. European Journal of Mineralogy, 9, 585-596.

Woods, D. and Bain, C. (2014) Total internal reflection spectroscopy for studying soft matter. Soft Matter, 10, 1071-1096.

Manuscript received August 7, 2019

Manuscript accepted March 4, 2020

Published online June 30, 2020

Manuscript handled by Masaki Enami 